\title{
On the Translation of English Hard News under Inter-cultural Background
}

\author{
Yurong Hao \\ School of Foreign Languages, Lanzhou City University, Gansu, China
}

\begin{abstract}
The author firstly introduced the characteristics of hard news form the perspectives of the structure, linguistic features and language style. Secondly, numerous cultural background factors are classified into six types including geographical environment, life style, traditional customs, religious beliefs, historical allusion and literature connotations which are the underlying causes of cultural barriers occurred in the hard news translation. To remove the cultural barriers, based on the Lawrence Venuti's (1995) foreignization and domesticaiton translation theory, the paper presents principles for hard news translation. By giving a large number of instances of hard news translations, this paper mainly focuses on such issues as the characteristics of hard news, the influence of the inter-culture on the hard news translation, and relevant translation strategies, and last but not least, attaches significance to the inter-culture awareness of the translator during the process of hard news translation.
\end{abstract}

Index Terms - hard news, translation strategies, inter-cultural awareness

\section{INTRODUCTION}

News refers to the timeliest report of events that have just happened, are happening, or are going to happen and it is born to meet the need of propagation and communication of information in human society. A piece of good news is considered as a combination of the loyalty to truth and the high quality of language.

News is rich in its content and variety raging form serious political and economic topics to relaxing travel information demonstrating the important events that people instinctively want to know from numerous dimensions. Both hard news and soft news are both originated from western journalism. The former one refers to serious and timely stories about important topics and it emphasizes on timeliness and objectivity and often applies to the on-the-spot report of news such as the befalling of some disasters, celebration of festivals and talks of national leaders. Whereas the latter one, the soft news, usually refers to feature and human-interests stories in which subjectivity is stressed and personal emotion and judgment are welcomed.

With the deepening of globalization, the exchanges and associations between different nations have become ever closer. Thus, as an essential communication tool in human society, hard news plays a vitally important role in international communication. In the hope of enhancing the mutual understanding between countries, translation--a seemingly irrelevant field to news--acts as a bridge between cultures. Meanwhile, hard news translation offers new perspectives and platform for people from different cultural backgrounds to view the world. As a result, the translation of hard news, especially the inter-cultural factors in hard news, has become significant and the inter-cultural awareness should be highly valued by the translator. And this paper aims at providing feasible translation tactics and procedure for the translation of English hard news under the background of inter-culture by analyzing cultural factors in English hard news and the inter-cultural awareness of the translator.

\section{LITERATURE REVIEW}

\section{A. Previous Studies on Translation of English Hard News under Inter-cultural Background}

A great number of books on news English and its translation have been published by Chinese scholars, and a great portion of books focus on hard news. For example, in Liu Qizhong's book English-Chinese News Translation, there is a chapter about the characteristic features of hard news (Liu Qizhong, 2002). In Xia Yande's book Practice Journalistic English Translation, the third chapter is mainly about the functions and features of hard news (Xia Yande, 1999). In accordance with these books, English hard news has particular style--- midget words, neologism, borrowed words, initialisms and acronym, and vivid word and common saying; they also have special grammatical features--- extended simple sentences, flexible use of tense, direct and indirect quotations, complex sentence pattern, and excessive use of passive voice. He Qishen's book Translation and Intercultural Communication explores deeper than books mentioned above in terms of news translation under the background of inter-culture in the fifth chapter (He Qishen, 2012). The book not only analyzes the functions and characteristic features of news, but also probes into the cultural factors in news English. It analyzes the correlation between news English, communication and the culture. However, there is no book focusing on English hard news from inter-cultural perspective exclusively, not to mention the translation of English hard news under inter-cultural background. 
As to papers published on journals, there are many about the news English, but not many about hard news English specifically, let alone the English hard news translation. Those about the translation of hard news offers translation strategies in accordance with the author's personal translation experience. However, all these translation strategies or tactics seem without being systematical studied. Only a few papers have applied translation theories to cultural factors in hard news. For instance, Deng Yuyang adopts Venuti's domestication and foreignization as the theoretical framework for his paper On the Translation of Journalistic English in Intercultural Communication (Deng Yuyang, 2011). He combines the cultural factors in hard news and Venuti's translation theory to prove his translation tactics reasonable. But the present author thinks that Deng's paper is not systematically organized. For instance, Deng's paper only probes the cultural factors in news English and the corresponding translation tactics, while the present author thinks further studies as the underlying causes of cultures differences in English hard news, the cultural barriers in hard news translation, the essence of translation of hard news as well as the inter-cultural awareness of the translator should be done and be attached great importance

\section{B. Theoretical Framework: Venuti's Domestication and Foreignization}

Domestication and foreignization are two translation strategies in terms of cultural factors translation. Domestication is the type of strategy with which we make translated text closely in line with the target culture. Foreignization is the strategy with which we try to retain the source information. These strategies have been debated for hundreds of years, but the first person who to studied them as translation strategies systematically was Lawrence Venuti.

According to Lawrence Venuti (1995), every translator is supposed to regard the translation process as an inter-cultural activity, and it is the translator's task to convey the message from the source culture to the target culture as much as possible. During translation each step is mediated by the different cultural values reflected in the target texts.

Thus instead of making target culture assimilate the differences in the source culture, an excellent translator would try to emphasize the foreignness in the source texts.

\section{FUNDAMENTALS OF ENGLISH NEWS}

News is a very commonplace literature style in people's daily life. However, to make a scientific definition of news is quite difficult. Although the uniform definition of "news" dose not exists, the widely-accepted definition in China's journal field is "news refers to the timeliest report of events that have just happened, are happening, or are going to happen." And the following are the news values which are helpful for deeper understanding of news.

\section{A) Timeliness}

The latest report of a current event is called the timeliness. From the definition of news, it can be seen that timeliness is of great importance.

B) Significance

Significance means that the event is of great significance or has profound influences on common people. The more influential the event is, the more newsworthy it becomes.

C) Prominence

People are interested in public figures and often pay great attention to their activities. The more important the figure is, the more newsworthy their activities are. Prominence is one of the news worthiness that determines the value of news.

\section{D) Proximity}

Proximity refers to the geographical or psychological closeness of the news being covered. Local news is usually much more valuable than international news that happened far away from the reader. In a nutshell, the event gets increasingly newsworthy, when it is increasingly close to readers geographically or psychologically.

E) Uniqueness

Uniqueness means that the report of those unusual, uncommon, or unexpected events could increase newsworthiness.

Those news reports of events that raise people's curiosity more often than not bring uniqueness to readers. And the uniqueness also increases newsworthiness of a piece of news, be it local or international.

F) Human interest

Those news stories involve human interest such as love, friendship, moral, often receives great attention from ordinary people, sine events of this kind can touch on their heartstrings. Therefore, those events of human interest are often of great values.

Ordinary people tend to pay attention to news reports that involve human interest such as love and friendship, because events of this type can touch on their heartstrings. As a result, human interest is one of the most important news values.

In a nutshell, the definition of news is "the timeliest report of events that have just happened, are happening, or are going to happen." Meanwhile, Timeliness, significance, prominence, proximity, uniqueness, and human interest are six 
values that determine the newsworthiness of news.

\section{A. Categorization of News}

According to different standards, news can be classified into different categories. For instance, based on the content involved in it, it can be classified into political news, military news and entertainment news, etc. But, there is one categorization method which can sufficiently reflect the essence of the news, that is, news can be classified into hard news and soft news according to its nature of occurrence.

\section{Hard News}

Hard news, also called "spot news" or "straight news", usually refers to "serious and timely stories about important topics." It emphasizes on timeliness and objectivity and often applies to the on-the-spot report of news such as the befalling of some disasters, celebration of festivals and talks of national leaders. The basic requirements of hard news are accuracy, objectivity and neutrality, which "concerns occurrences potentially available to analysis or interpretation and consists of factual representation' of occurrence deemed newsworthy." It transmits the latest news with no delay. The subjects like disaster, economics, diplomacy, and politics are often considered as material of hard news.

\section{Soft News}

Soft news refers to pieces of news with strong emotional factors and vivid style, and it is characterized as news telling stories aiming at entertaining readers instead of merely informing them.

\section{B. Linguistic Features of English Hard News}

\section{Lexical Features}

Midget Words. The frequent use of midget words is one of the most distinguishing lexical features of English news. For example, the following midget words are usually used instead of complicated words in English hard news.

TABLE $1-1$

MIDGET WORDS AND THEIR CORRESPONDING COMPLICATED WORDS

\begin{tabular}{|l|l|}
\hline Midget words & Complicated words \\
\hline boost & increase \\
\hline move & action, decision \\
\hline ban & prohibit, interdict, restraint, refuse \\
\hline cut & abridge, abbreviate, shorten, curtail, reduce \\
\hline aim & design, intention, purpose, objective \\
\hline try & endeavor, experiment, attempt, effort, striving \\
\hline
\end{tabular}

Frequent Use of Neologism. Neologism, also known as new words, is very common in English hard news. The reason for the frequent use of neologism is very obvious. Hard news should keep abreast with the times, which is ever-changing in modern life. As a famous saying goes, "Nothing endures but change." And hard news should keep track with those changes. For instance, such new words as transion, greentech, ecotourism, which effectively reflect the lifestyle of modern people, have become very popular in hard news.

Borrowed words. A large number of borrowed words being used in newspapers is a striking feature of news writing. The major purposes of using borrowed words are to express the meaning more appropriately on the one hand and to attract readers on the other hand. The words sauna, sashimi, oolong, ad hoc and encore are often used in English news, but they originate from Finnish, Japanese, Chinese, Latin and French respectively.

Initialisms and Acronym. Initialisms and acronym, is usually the short form of a proper name, technical term, or a phrase. Proper use of initialisms and acronyms can greatly save the space of English news and reader's reading time. For instance, following initialisms and acronym often used in English new, especially in hard news.

TABLE 1-2

INITIALISMS OR ACRONYM AND THEIR ORIGINAL WORDS

\begin{tabular}{|l|l|}
\hline Initialims or acronym & Original words \\
\hline API & Air Pollution Index \\
\hline FBI & Federal Bureau of Investigation \\
\hline NATO & North Atlantic Treaty Organization \\
\hline AIDS & Acquired Immune Deficiency Syndrome \\
\hline OPEC & Organization of Petroleum Exporting Countries \\
\hline
\end{tabular}

Vivid Word and Common Saying. The value of hard news cannot be realized without readers' attention. So how to attract readers and arouse their reading interests should be the priority of hard news writing. In order to strike the audience or readers, news language must be vivid and distinctive. In general, vivid words and common sayings can arouse readers' associations, which just like vivid and lively pictures in their minds. The following examples can best illustrate this point.

These migrant people flooded the cities, exacerbating already strained urban resources.

To roars of jubilation, Bill Clinton moved into the White House, ushering in a new party, a new generation and an altogether crowd of people, exulting in their diversity. "This is our time," declared the third youngest US president.

They could include widespread hunger and joblessness, accompanied by environmental devastation and cancerous 
urban growth.

In the above three examples, verbs are adopted very vividly thus making readers form a motion picture in their mind. By employing words of this kind, the whole news report would be filled with vividness as well as liveness.

\section{Grammatical Features}

Extended Simple Sentences. In order to make readers have the sense of objectiveness and timeliness of news English, hard news prefers to focus on the current event or something happened before, in this case, there is a good way called the extended simple sentence.

Flexible Use of Tense. In English news writing, tense is often flexibly adopted. For example, past tense is usually used to report the events happened previously, and the future tense is mainly employed to tell readers the influence that the mentioned event could probably have. The following example can illustrate the point.

Direct and Indirect Quotations. To a great extent, hard news is to record what people say. That is to say, quotations are significant parts in English hard news. Quotations can make the news more vivid and authentic on one hand, and can also demonstrate the objective stance of news English, as a result, hard news more often than not quotes people's words frequently. In general, there two types of quotations, which are respectively the direct quotation and the indirect quotation. The direct quotation is adopted when what one says are so well-stated, vivid and significant that readers should be informed of the precise words.

Complex Sentence Pattern. In order to better fulfill the impartation and communication function of English hard news, the sentence pattern of hard news should be concise and simple as much as possible. As a result, most sentences in news text are simple sentences. In fact, in hard news, there are also some long and complex sentences in English hard news. However, it is important to know that simple sentences do not mean easy sentences, while complex sentences are not always so complicated to understand.

Excessive Use of Passive Voice. Compared to other styles, passive voice is used excessively in English hard news. What's more, English hard news also tries to show people the valuable information. Passive voice is often employed to show the results in a news as to attach great attention to the six factors, which includes who, what, when, where, why and how. This can be well illustrated by the following English hard news report.

In this news report, a large portion of verbs are adopted as passive voice. This not only brings conciseness to the whole text, but also can give readers a sense of authority. As a result, the use of passive voice in English hard news is excessive.

\section{Cultural Factors ANd Cultural Barriers}

Every country possesses its unique social background, cultural features and mindset. When the historical and cultural factors in source language cannot be found in target language, words in a language will not have their equivalents in another language.

With profound cultural background and a long history, many cultural allusions have their deeper meanings. They are short and brief, but rich in meaning. For instance, in some English speaking countries, Christianity enjoys great popularity, thus many allusions and idioms have their origin from the Bible, such as the salt of the earth(社会精英 she hui jing ying), separate the sheep from the goats (分清良莠 fen qing liang you) etc. As an integral part of culture, religion is a sensitive area and should be attached great importance to.

Every culture has its unique value system and mindset, so different mindset may hold different views upon same news fact. Chinese reports often focus on the bright side of things, people always expect good things happen, while Western reports pay more attention to the objectivity of things. For example, when the massive earthquake struck China's Wenchuan, Chinese media's focus is the heroic deeds in the disaster relief, whereas western reporters show the public more details in the spot and inform people of the damage and mortality caused by the quake. In addition, in Western culture, individualism is highly valued, and people do not like to be told how to do things. But in China, news reports, especially reports on politics, frequently adopted phrases such as "we should". Moreover, hard news usually refers to serious and timely stories about important topics, and such subjects as disaster, economics, diplomacy, and politics are often considered as material of hard news. On the other hand, China and Western countries belong to different political systems, thus having their different, sometimes even contrary, national interest. For instance, Western media may hype the truth when that reports the Chinese corrupt officials' crime and the corruption problem in China's political system in an attempt to destroy China's international reputation. And translators need to be cautious about the words they translated into target language and protect China's positive image.

In a nutshell, due to the untranslatability of cultural perspectives, numerous cultural barriers in the translation of English hard news come into being.

\section{A. Cultural Factors in English Hard News}

The cultural factors that a translator will encounter when translating the English hard news are numerous, but they can basically be classified into six types which are respectively geographical environment, lifestyle, tradition and customs, religious belief, historical and cultural allusions, and literary knowledge.

\section{Geographical Environment}

Since every ethnic group's living conditions vary from one to another, the different ethnic groups hold widely 
differing views on the same subject. Geographical culture attaches particular meaning to words. Taking some Chinese idiom for example, “有眼不识泰山”, “重于泰山”, and “稳如泰山” are all related to Mount Tai(one of the five most famous mountain in China ), which is often used to symbolize respect, solemn, and greatness in Chinese culture. Likewise, the English idiom "all roads lead to Rome" means there are multiple ways to get to the same goal. It is originated in Ancient Rome, as whenever the Roman army successfully conquered a nation, they built a concrete road starting from that nation to Rome.

\section{Lifestyles}

Language is closely related to language environment, culture, and society and cannot be apart from them. Different material conditions and historical experience shape distinctive characteristic features of different ethnic group, thus resulting in various lifestyles. Therefore, language---the product of culture---is painted with strong ethnic color. This point can be best illustrated by the following example.

Had he come face to face with exiled Iraqis in west London, however, it's likely the reception he faced would have been more passionate.

要是他在伦敦富庶区与那些背井离乡的伊拉克难民当面接触的话，那么，他会受到更热情的欢迎的。

"West London" in this sentence has particular political meaning. Geographically, London is divided into west part and east part, and the west part is called "West End" which is also the region where rich people reside in. Whereas, the "East End" refers to the slum area where poor people live. If readers have a clear sense of the British culture, they should know that a ordinary Iraqi cannot afford the expense of immigration to U.K.

\section{Tradition and Customs}

Language comes from life, and the lifestyle led by certain group of people has strong influence on their language and communication system. For example, the number "eight" is Chinese favorite number, because it is a homophone for "make a fortune" in Chinese. While English word "eight" does not have this meaning. Similarly, English word "pear" sounds like "pair" thus forming alliteration. But the word "pear" in Chinese does not symbolize "pairs" or "couples", since it is a homophone for "separation" which means to leave or to separate.

\section{Religious Belief}

Religious belief is so influential to people's life that it even gives some new meanings to their daily language. Differences between Western and Eastern religions have important impact on the translation between English and Chinese. In Western world, Christianity is the dominant religious culture which has a profound influence on people's language performance. The European continent was falling apart when Christianity was born, and nothing could bring peace to world. Even the secular power--- the kingship was in desperation. So people began to believe that only the almighty God could conquer the people's insatiable ambition for power, then Christianity emerged at this historic moment. English idioms such as "Man proposes, God disposes" and "God helps those who help themselves" are all related to Christian culture. And “老天爷” in Chinese is a reflection in upon the Buddhism culture which is also the dominant religious culture in China.

\section{Historical and Cultural Allusions}

Every ethnic group has its own path of development, thus resulting in different allusions to represent particular meaning. For example, "to meet one's Waterloo" is originated from Napoleon Bonaparte and his battle with the duke of Wellington leading the British, the German and the Dutch. It means to meet someone crushing defeat. Likewise, “败走 麦城” is the Chinese idiom to describe a disastrous defeat, and the origin of this phrase comes from Guan Yu, a famous general of Shu during Three Kingdoms Period, and his crushing failure in Mai city which was also a vitally important military area. Therefore, a good command of ethnic history and culture is required when this kind of allusions is translated.

\section{Literary Knowledge}

Mythologies, legends, and literary classics created a wide range of idioms, which are the reflection of both ethnic features and social characteristics. Also, they add vividness and liveliness to language thus making the language with strong expressiveness. For example, the Greek proverb "swan song" is often used to describe the final work of a poet or musician with its origin in a Western mythology that a swan sang the saddest and the most beautiful before it died. Another Greek proverb is "sour grapes" from Aesop's Fables, and it is often referred to something that is within one's sight but beyond one's reach. Likewise, Chinese idioms such as “往事具备只欠东风” and “逼上梁山” are originated from Chinese literature classics Romance of Three Kingdoms and Water Margin respectively, and also add distinctiveness and vividness to Chinese. When translating the idiom of this kind, the translator should have respect for the culture-loaded words, and provide the target readers with equivalent enjoyment that source language readers may have.

The cultural factors in translation of English hard news are extremely commonplace, and translators should have a macroscopic grasp of the cultural factors in translating English hard news.

\section{B. Cultural Barriers to the Translation of English Hard News}

People who do not know about translation tend to propose that one language can be translated into another accurately with a good bilingual dictionary. And this is a very common mistake. Unfortunately, language translation is difficult since there are so many misinterpretations. All languages are closely bound to its own culture, and word-for-word 
translation is difficult if not impossible. Even when the adequate interpretations of the original text are provided by the translation, the full equivalence cannot be achieved. Given such circumstances, the values of English hard news would not be reached.

There are some examples showing that how hard the foreign translation is and sometimes the improper using of words would result in the totally opposite meaning. We can also draw a conclusion that the translators are supposed to link the different languages and even the different cultures together. Some researches related to language show that the language can reflect the culture ideas to some extent, and the translator can use the different meaning of words to break the culture obstacle and deliver the emotions.

Most English speakers in China tend to agree that there is a link between propaganda and “宣传” and they can be translated to each other. For example, "The Propaganda Department of the Central Committee of the Communist Party of China” can be translated to “中共中央宣传部”, but there would be misunderstanding while communicating because of the different cultures. What's more, the "The Publicity Department of the Central Committee of the Communist Party of China ”, which is translated from “中共中央宣传部”, is resulted from the changing of the cultural view. However, there must be some troubles if the two words of different languages can't find a way to equally translated to each other. In a conclusion, considering the cultural difference while translating in English hard news is of great importance.

In the above examples, due to the cultural barriers between Chinese and English, the Chinese word 宣传 is translated into propaganda and publicity respectively. And it can be seen that the former translation fails to convey the original meaning of the source text and the significance, prominence, and human interest of it are lost, which not only makes the loss of hard news values but also the misunderstanding between cultures.

Conveying the meaning and style of the source language is one of the goals of translation. However, dictionary translations do very little help to achieve such goals since they seldom reflect the common language usage in a culture. Meanwhile, people from monolingual culture tend to assume that words in a language should have their equivalents on another language. As a result, a language leaner may search for the equivalents of his or her native language in a bilingual dictionary in order to speak a new language. This kind of mindset towards the vocabulary of two language is harmful to language learning process since words are "symbols for dynamic and explicit features of the culture" (Nida, 1975, p.147). This can be a serious problem if a bilingual dictionary becomes the sources of equivalents.

To sum up, when dealing with the difficulties of English hard news translation, the six values are of great importance and cannot be neglected, because as mentioned above, they are often used to determine the newsworthiness of news. What's more, timeliness, significance, prominence, proximity, uniqueness, and human interest are not only the features of English hard news, but also make a good Chinese version of hard news.

\section{TRANSLATION OF ENGLiSh HaRd NEWS}

\section{A. The Essence of the Translation of English Hard New}

The translation of English hard news is aimed to inform Chinese people of the current events of politics, economy, and science and technology etc. of the world and to enable Chinese people to have a better understanding of the target language culture. Meanwhile, the translation of English hard news, in its essence, is an inter-cultural activity. And different cultures lead to different value system and mindset.

As mentioned above, hard news refers to ideological, instructive and informative reports on politics, economy and science and technology. Also, hard news has influence on people's vital interest and their survival in society, thus being the reference for daily activity. A country's political, economic, and scientific and technological events of great importance are closely bound to the culture of its own, therefore, the translation of English hard news interprets the target language culture and the essence of English hard news translation is to translate cultures. In a word the translation of English hard news is an inter-cultural activity.

Culture is collective by nature in that it is shared with those who live or lived in the same social context, in which culture was learned. British anthropologist Edward B. Tylor postulates in his book Primitive Culture, "Culture is the complex whole which includes knowledge, beliefs, art, morals, law, custom and many other capabilities and habits acquired by man as a member of society.'(Brook Tylor, 1871, p.69) Geert Hofstede from Netherlands defines culture in his book Culture's Consequences as "the collective programming of the mind distinguishing the members of one group or category of people from another." Since translation of English hard news is an inter-cultural activity, it requires comprehensive capacities from translators. In addition, the translators tend to meet with various topics, and they have to be very knowledgeable and informative. In order to reflect different range of topic of English hard news, the first thing translators must do is that they need to have a good understanding of different topic represented by both source language and target language to eliminate intercultural misunderstanding. To translate English hard news, translators should understand how target language readers see things and how they express themselves. translators of English hard news should understand clearly the real meanings in source language's cultural features, and should choose correct expressions of target language.

In a nutshell, the essence of English hard news is an inter-cultural communication in which culture of source language is transformed into culture of target language.

\section{B. Translation Problems and Translation Strategies of English Hard News}


As is known to all, language is complicated phenomenon. Although most of the differences between two languages can be translated, still some are too difficult to find proper explanations due to the untranslability of cultural perspectives. Therefore, translators should raise inter-cultural awareness of "the other culture" to bridge the gap between different cultures. And with Venuti's translation theory of domestication and foreignization, translators can found out the purpose of the literal translation, free translation, and combination of literal or free translation with explanations.

\section{Literal Translation}

There is a way of translating called direct or literal translation which demands the two languages are same with each other in form, structure and so on. The aim of direct translation is that the readers after reading the version after translated will have the same thought as what they think after they read the original one. However, it is not refers to the "word-for-word" translation, mainly because there would be some changes in literal translation in order to make it acceptable. The literal translation should be based on that the two languages should have similar linguistic parts which include vocabulary, grammar, rhetorical devices and so on, and the biggest advantage of the literal translation is that the meaning and the style after translated are kept the same as the original one. It can be best illustrated by the following example.

(1) a. Mother Nature turned freakishly fickle this week, unleashing her ferocity upon Australia's southeast coast and delivering one of the most bizarre summer weather patterns on record.

b. 大自然母亲的情绪在这星期极为变幻无常。澳大利亚南部海岸遭受了她狂暴的洗礼, 经历了历史上最不寻 常的夏季天气。

The source text is a report on weather, the nature is personified as Mother Nature, adding liveliness to a relatively dull weather report. And the personification is remained in the target language.

\section{Free Translation}

There is a special style called free translation which focuses on the ideas and content rather than the linguistic aspects such as forms or words which not refers to reconstruction actually. The free translation is useful instead of the literal translation if the two languages are expressed in different ways.

(1) a. English cannot be fed with the east wind of a narrow rationality.

b. 英国的特点和精神不能靠寒风般肃杀的狭险理性来维持。

The phrase has its origin from the Britain's locality. In Britain, westerly ocean wind usually keeps the weather mild and warm, while ocean wind from the east always brings the temperature down. And the opposite goes to China's climate where west wind means cold weather and east wind means warm weather. Therefore, it is reasonable in the source text to compare "narrow rationality" to "east wind".

(2) a. The Present's speech reminds the public of a British Sunday.

b. 总统的演讲给人刻板、乏味的感觉。

Bound by strict religious belief, the devout British Christians go to church every Sunday instead of other recreation places. So from others' perspective, the British's Sunday is rather boring and dull.

(3) a. The injection of public funds may plug the hole in Japan's economic Titanic.

b. 公共资金的注入或许会堵上将要下沉的日本经济巨轮的漏洞。

The ship -- Titanic struck an iceberg on her maiden voyage when she left fromEngland heading for New York City, and she sank at last on 15 April 1912. And it is used as a metonymy to describe the critic situation of Japan's economy.

(4) a. He and his allies are David, taking on the gambling Goliath.

b. 他和他的同盟们是弱小的，而他们要挑战的对方确实孤注一掷而强大的。

"David" and "Goliath" are figures from the Bible. And according to the Bible, Goliath and his giant soldiers were challenging the King (Saul). Everyone was terrified of Goliath and didn't want to fight him. David, a young teenager, volunteered to fight Goliath and confronted him with only the weapons: a slingshot and a few rocks. It is a story about the weak overcoming the strong.

\section{Literal Translation plus Explanation}

This strategy is an extension to literal translation and shares the same advantages with it but it is easier for readers to understand.

(1) a. Drug dealers have a strong preference for the restricted cocaine probably on the theory of forbidden fruit.

b. 毒贩们对那些被禁的可卡因情有独钟, 这或许是“禁果定律” (越被禁止的东西, 人们越想得到) 在起作 用吧。

Forbidden fruit is a phrase from Bible. It is a metaphor, indicating the indulgence or pleasure considered illegal or immoral. The "forbidden fruit" is translated literally, but the explanation shows the connotative meaning.

\section{Transliteration}

Transliteration is a way of picturing the writing of original one into another. In order to make the translation without any losses, the reader should have the ability to reconstruct the spelling of words. The transliteration sometimes needs to find some complicated ways to make the words in accordance with the original one after translated. When talking about hard news, it always goes with different current events including many names, such as people's names, name of workplace, name of city, and name of country etc., and many new words. In this way, the transliteration becomes the 
most popular way to do with these names and words, and greatly used in hard news translation.

TABLE 5-1

EXAMPLES OF NAMES ARE AS FOLLOWS.

\begin{tabular}{|l|l|l|}
\hline \multirow{2}{*}{ Name of person } & Chamberlain & 张伯伦 \\
\cline { 2 - 3 } & Barack Obama & 巴拉克 奥巴马 \\
\hline \multirow{3}{*}{ Name of company } & Asics & 爱世克斯 \\
\cline { 2 - 3 } & Adidas & 阿迪达斯 \\
\hline \multirow{2}{*}{ Name of place } & Kathmandu & 加德满都 \\
\cline { 2 - 3 } & Barcelona & 巴塞罗那 \\
\hline Name of country & Ecuador & 厄瓜多尔 \\
\cline { 2 - 3 } & Italy & 意大利 \\
\hline
\end{tabular}

TABLE 5-2

EXAMPLES OF NEWS WORDS AND BORROWED WORDS ARE AS FOLLOWS.

\begin{tabular}{|l|l|}
\hline English Name & Chinese Name \\
\hline cool & 酷 \\
\hline disco & 迪斯科 \\
\hline OPEC & 欧佩克 \\
\hline IELTS & 雅思 \\
\hline TOEFL & 托福 \\
\hline Teflon & 特氟龙 \\
\hline Yuppies & 雅皮士 \\
\hline EURECA & 尤里卡 \\
\hline Beatles & 披头士 \\
\hline punk & 朋克 \\
\hline hacker & 黑客 \\
\hline clone & 克隆 \\
\hline
\end{tabular}

\section{Transliteration plus Explanation}

This translation strategy is an extension to transliteration. The latter can raise the reading interest of Chinese readers, but to those whose mother tongue is English, it is less acceptable. Therefore, the strategy of translation plus explanation can best solve the problem.

From the discussion above, we can see that literal translation and free translation are two main methods used in translating the hard news. An excellent translator should use them properly and proficiently at the same time. When it comes to the selection of methods, the inter-cultural awareness of the translator plays the key role, thus the translator could apply either of the two or the combination of the two with some explanations in accordance with the specific contexts.

Each method has its own strength. In the mind of the author, literal translation deserves primary attention in order to keep the original flavor because more similarities exist than disparities between the two languages regarding hard news translation. When the original meaning cannot be conveyed in its original form, we can translate the meaning to the readers first. In some special occasions, some explanations are needed to add into the free translation for the purpose of conveying the correct information.

\section{Translator's Inter-cultural Awareness}

As mentioned above, the translation of English hard news is aimed to inform target language readers with the message from the source language reporters, but, more importantly, provide them with equivalent education, enlightenment, and the enjoyment of literature reading to those of source language readers. To achieve this goal, news translators not only need to have a good command of both target and source language but also need to have an inter-cultural awareness. There are many challenges in the process of translation in that translation itself is not simple conversion between two languages, but a process of intercultural communication. The task of the translator is not only to translate the texts, but to interprete the cultural connotations in the source texts.

The meaning of intercultural awareness has long been explored by experts and scholars from different perspectives. It is regarded as a process of attitudinally internalizing "insights about those common understandings hold by groups that dictate the predominant values, attitudes, beliefs and outlooks of the individual" (Adler, 1987, p.67). Such a process includes three levels, i.e. the awareness of superficial cultural traits, the awareness of significant and subtle cultural traits that contrast markedly with ours, and the awareness of how another perspective (Hanvey, 1987).

According to Chen Guoming (2010), inter-cultural awareness refers tothe inter-cultural communication competence in cognitive aspect; it is the understanding how cultural conventions can influence our thinking and behovoir.

Despite these definitions given by scholars and experts, there are some common features shared by inter-cultural communication awareness. the first feature is that the effect of culture on human behaviors is strongly obvious in the definitions. Second, the recognition of the differences between various cultures is of great important. In conclusion, we can define inter-cultural communication awareness as the cognizance of different cultures when we communicate with 
others.

From the above discussion, it is understood that translators should have strong the inter-cultural awareness when he or she participates in the process of the inter-cultural communication. It is a particular way of thinking, a criterion for judgment or an clear sensitivity born by the interpreter. Thus, a successful translation is the result of accurately understanding and reconstructing and appling various skills and techniques professionally, and meeting the professional standards.

\section{CONCLUSION}

With its own linguistic features, hard news has a special style features of great accessibility conciseness and vividness. Due to its timeliness and brevity, new words, acronym, and vivid words are very commonplace in hard news. Also, since Chinese and English belong to different language families, Chinese and English hard news differ significantly in grammar and syntactic structure with English hard news rich in complex sentences and Chinese hard news full of polished rhetorical sentences. Moreover, differences in value system and mindset of Chinese culture and the culture of English-speaking countries cause a wide range of cultural barriers in the translation of English hard news. Therefore, the hard news translation is also an inter-cultural activity.

Translating English hard news does not only mean having practical skills; it is also an art which requires a strong inter-cultural awareness from translators. The translators should overcome the barriers of language and culture. Translators should try to expand their inter-cultural knowledge and enhance their inter-cultural communication competence. In doing so, they need to focus on the linguistic and cultural differences and avoid misunderstanding and mistranslation, so that the purpose of inter-cultural communication can be fulfilled.

By analyzing features of English hard news, cultural factors in English hard news, and the relation between the two, this paper postulates five translation strategies to deal with the cultural barriers and stressed the importance of translators' cultural awareness. Of course, there is still plenty of room to improve in this paper. And it is the author's hope that more researches can be done in the field of English hard news translation, and it is believed that the effort and research in this area, if it is sufficiently funded and supported, will contribute to a better mutual understanding between China and the world.

\section{NOTES}

This paper is supported by National Social Science Foundation of China (Grant No.: 12BYY016) and "12th Five-Year" planning project of Gansu Provincial Education Department (Grant No.: GS[2015]GHB0171).

\section{REFERENCES}

[1] Adler, P.S. (1987). Culture Shock and the Cross-cultural Learning Experience. Oxford: Oxford University Press.

[2] Bao, Huinan. (2001). Cultural Context and Translation. Beijing: China Translation \& Publishing Corporation.

[3] Deng Yuyang. (2011. Discussion on English News Translation from the Perspective of Inter-cultural Communication. Journal of Yulin Normal College, 3, 33-37.

[4] Gan Xifen. (1993). Dictionary of News Study. Zhengzhou: Henan People's Press.

[5] Hanvey, R.G. (1987). Cross- Culture Awareness. Miami: American Academic Press.

[6] He Qixin. (2012). Translation and Intercultural Communication. Beijing: Foreign Language Teaching and Research Press.

[7] Hofstede, Geert. (2008). Concluding Cultures. Shanghai: Shanghai Education Press.

[8] Li Changshuang. (2009). Translation of Non-fiction. Beijing: Foreign Language Teaching and Research Press. 2009.

[9] Liu Qizhong. (2009). Translation of Chinese Hard News. Beijing: Qinghua University Press.

[10] Liu, X. (2008). Intercultural Business Communication. Tianjin: Nankari University Press.

[11] Nida, Eugene A. (1993). Language, Culture and Translating. Shanghai: Shanghai Foreign Language Education Press.

[12] Tylor, Brook. (1871). Primitive Culture. Cambridge: Cambridge University Press.

[13] Venuti, Lawrence. (1995). The Translator's Invisibility -- A History of Translation. London \& New York: Routledge.

[14] Xia Tingde. (1999). Practical Translation of News English. Beijing: University of International Business and Economics Press.

[15] Xu Mingwu.(2003).News English and Translation. Beijing: China Translation \& Publishing Corporation.

[16] Zhang Jian. (1994). Stylistic Analysis of News English. Shanghai: Shanghai Foreign Language Education Press.

[17] Zhu Yongtao. (2005). Introduction to Societies and Cultures of English Speaking Countries. Beijing: Higher Education Press.

Yurong Hao, born in Gansu, China in 1978, gained a M.A. degrees in Translation Theory and Practice in School of Foreign Languages, Northwest Normal University in 2010 and now is a fourth-year Ph.D. candidate of Curriculum and Teaching Methodology in School of Education, Northwest Normal University, China. She is currently an associate professor in School of Foreign Languages, Lanzhou City University, China. Her research interests include translation theory \& practice, and English Pedagogy. Professor Hao was a visiting scholar in Manchester University, UK in 2014. 